\title{
PEMBERDAYAAN PENGRAJIN KAPAL KAYU DI KABUPATEN BATANG DENGAN KKN-PPM TEMATIK
}

\author{
Wilma Amiruddin ${ }^{1}$, Andi Trimulyono ${ }^{1}$, Bandi Sasmito ${ }^{3}$ \\ ${ }^{1)}$ Jurusan Teknik Perkapalan, Fakultas Teknik, Universitas Diponegoro \\ ${ }^{2)}$ Jurusan Teknik Geodesi, Fakultas Teknik, Universitas Diponegoro \\ Email: a wisilmiw@yahoo.com
}

\begin{abstract}
Abstrak
Kabupaten Batang terletak di pantai utara Jawa Tengah dimana wilayah pesisir kabupaten ini terdapat potensi yang dapat dikembangkan menjadi aset yang berharga bagi bangsa yaitu para pembuat kapal tradisional namun pembuatan desain kapal yang ada memiliki keunggulan dari segi stabilitas dan kamar mesin yang didalam/engine in board. Perlunya pendampingan pada proses produksi agar desain tetap terjaga namun tidak kalah dalam teknologi. Untuk menyelesaikan permalahan tersebut maka tim pengabdian dari Jurusan Teknik Perkapalan akan melakukan kegiatan KKN-PPM tematik. Berdasarkan permasalahan yang ada pada mitra maka pelaksanaan KKN-PPM tematik ini akan dilakukan sosialisasi serta pelatihan penggunaan program Fishipro untuk desain kapal dan konstruksi kapal kayu serta menggunakan program desain kapal Delftship, Maxsurf dan ProCAD untuk desain Propeller. KKN-PPM tematik telah berhasil dilaksanakan di galangan kapal kayu di Karangasem Utara dengan beberapa luaran telah tercapai, baik dalam program kerja mahasiswa KKN-PPM monodisiplin maupun multidisiplin

Kata kunci: Kapal Tradisional, Fishipro, KKN-PPM tematik.
\end{abstract}

\section{PENDAHULUAN}

\subsection{Latar Belakang}

Armada kapal perikanan nasional, sampai dengan saat ini, masih didominasi oleh berbagai jenis perahu dan kapal penangkap ikan tradisional Umumnya, kapal ikan tradisional terbuat dari kayu dengan ukuran kurang dari 30 GT dan dibangun oleh galangan atau pengrajin kapal kayu tradisional, sehingga mempunyai corak yang spesifik untuk masing-masing daerah. Karena sifatnya tradisional, maka acuan dalam pelaksanaan pembangunannya tidak berdasarkan gambar rancang-bangundan spesifikasi teknis yang lengkap, melainkan berdasarkan pengalaman yang dimiliki secara turun-temurun dan mengikuti sistem tradisi masyarakat setempat(Oktavian,2008). Kabupaten Batang merupakan salah satu kabupaten yang memiliki potensi untuk produksi kapal. Produk kapal galangan kapal kayu di Batang memiliki beberapa keunggulan dibanding kapal tradisional lain yaitu; stabilitas yang baik dan mesin utama berada di dalam (In board engine).

Untuk lebih memudahkan pihak galangan kapal kayu tradisional dalam pembuatan gambar lines plan diperlukan sebuah perangkat lunak (software) yang dirancang khusus untuk pembuatan lines plan kapal perikanan berdasarkan data dari kapal-kapal yang sudah dibangun di galangan rakyat terutama untuk kapal perikanan daerah Batang. Dari pengabdian ini diharapkan dapat membantu untuk mengetahui spesifikasi teknis kapal yang dibangun yang dapat berupa gambar teknis menggenai bentuk kapal secara melintang maupun memanjang, bentuk kurva hidrostatik yang akan bermanfaat untuk mengetahui karakteristik kapal yang dibangun yang meliputi data mengenai koefisien bentuk kapal dibawah garis air (CB,CP,CM,CWL), luasan permukaan Basah(Wetted surface area), luasan garis air (Water plan area), data menggenai titik berat,titik apung kapal baik secara melintang maupun memanjang (LCB,LCG,KB,MG) dan karateristik kapal lainnya. Sedangkan dilain pihak pembangunan kapal kayu untuk tujuan kegiatan usaha penangkapan ikan memerlukan teknik pengerjaan yang sesuai dengan prosedur dan persyaratan yang diatur berdasarkan ketentuan yang berlaku serta sesuai dengan standar yang telah ditetapkan dalam Biro Klasifikasi Indonesia. (Agung, 2011)

Kabupaten Batang merupakan salah satu kabupaten yang memiliki potensi untuk produksi kapal. Dilihat dari segi produktifitas galangan, terbukti CV. Laksana Abadi sebagai galangan kapal tradisional mampu memproduksi kapal berjumlah 18 unit dalam jangka waktu 12 bulan. Karena sifatnya tradisional maka proses pembuatan dapat dikatakan menggunakan metode masih sangat tradisional dan kepercayaan mereka terhadap perkembangan teknologi sangatlah rendah ini terlihat dari cara pembangunan kapal masih tradasional. Hal ini menyebabkan perlunya transfer pengetahuan 
tentang pembangunan kapal secara modern kepada perajin kapal di kabupaten Batang terutama dibidang kurva hirdostatik maupun konstruksi kapal kayu agar pemahaman masyarakat mengenai rancang bangun kapal lebih baik lagi terutama pada proses pembuatan kapal baru tanpa menghilangkan karakteristik kapal daerah Batang

\subsection{Tujuan}

Adapun permasalahan yang dihadapi oleh Pengrajin kapal tradisonal mitra secara rinci yang menjadi prioritas adalah sebagai berikut :

1. Teknik rancang bangun kapal kayu di kabupaten Batang belum memiliki gambar teknik pada kapal bangunan barunya.

2. Kurangnya pemahamanan tentang teknik pembangunan kapal secara modern terutama keutamaan gambar teknik.

3. Tidak adanya pengetahuan mengenai gambar kurva hidrostatik yang menggambarkan karakteristik kapal kayu.

Perlunya pengetahuan para pengrajin untuk mengetahui standar baku konstruksi kapal kayu dengan BKI.

\section{TINJAUAN PUSTAKA}

\subsection{Program Fishipro}

Fishipro merupakan program aplikasi yang dikembangkan oleh tim dari Jurusan Teknik Perkapalan Universitas Diponegoro dimana aplikasi program ini merupakan desain kapal kayu untuk tipe Batang dimana data utama didalam program aplikasi Fishipro meruapakan kapal-kapal yang dibangun digalangan kapal kayu di Kabupaten Batang.

Fishipro sendiri dikembangkan untuk memudahkan proses desain kapal kayu dimana desain akan diambil dari database yang ada pada program Fishipro sehingga setelah desainer melakukan inputan parameter dimensi kapal maka akan didapatkan desain kapal yang sesuai dengan parameter yang telah di masukan.

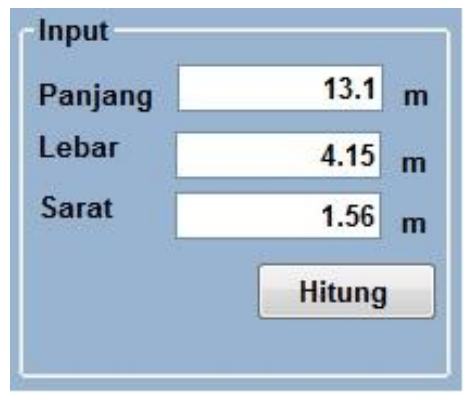

Gambar 2. Inputan untuk program Fishipro

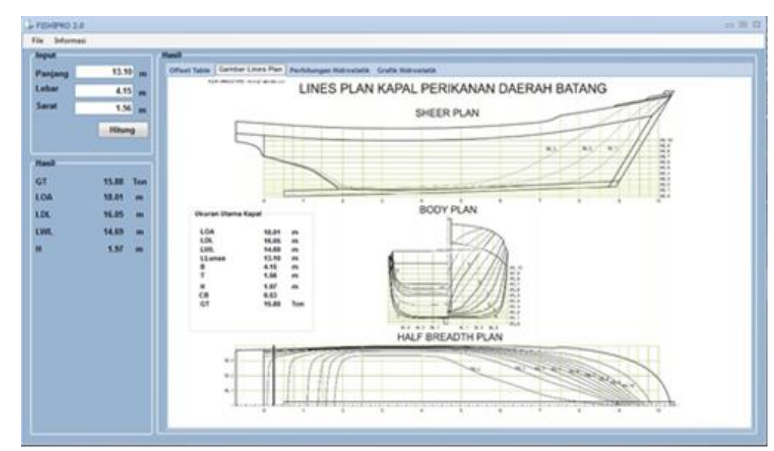

Gambar 3. GUI interface dari program Fishipro

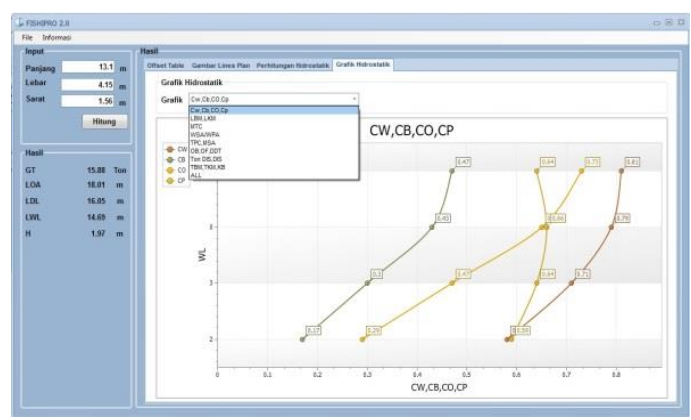

Gambar 3. Out put dari program Fishipro

Setelah input dari ukuran utama kapal maka langkah selanjutnya akan dicari bentuk lambung kapal yang sesuai ukuran utama kapal yang di inginkan dengan cara interpolasi yang terdapat pada database yang ada maka setelah dilakukan perhitungan dan telah memenuhi kriteria inputan maka hasil dari software tersebut adalah koordinat lambung kapal kayu yang sama seperti yang pengrajin bangun. Database yang digunakan oleh perancang software adalah kapal kayu yang pernah dibuat oleh pengrajin atau kapal kayu kabupaten Batang sehingga karakteristik kapal akan sama dengan yang dibuat oleh pengrajin kapal kayu. Output dari software dapat digunakan untuk penggambaran Rencana Garis kapal bangunan baru sehingga perlunya pemahaman dari perancang software ke pengrajin kapal kayu agar terjadi transfer ilmu kepada para pengrajin kapal kayu.

\subsection{Program Konstruksi Kapal Kayu}

Dalam kegiatan pengabdian ini untuk memberikan pengetahuan mengenai desain konstruksi kapal kayu maka akan digunakan aplikasi yang telah dikembangkan oleh jurusan Teknik Perkapalan dimana program tersebut Fishing Vessel construction yang dikembangkan oleh mahasiswa dan dosen Jurusan Perkapalan. 
Program aplikasi ini merupakan aplikasi dari aturan BKI mengenai kapal kayu tahun 1996[3] karena minimnya akan sertifikasi kapal kayu maka peraturan ini tidak banyak berkembang dibandingkan kapal baja. Seperti halnya program Fishipro maka program ini memiliki database mengenai aturan dimensi profile kayu yang ada pada peraturan BKI 1996 sehingga dengan inputan parameter dimensi kapal akan didapatkan dimensi profile kayu yang akan digunakan dalam pembuatan kapal.

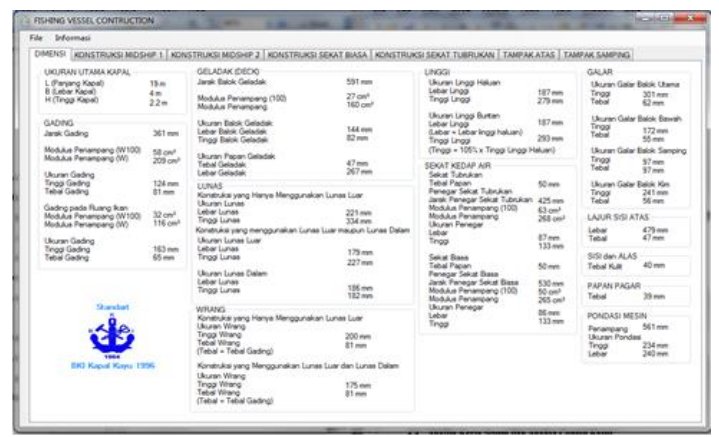

Gambar 4. Out put dari program konstruksi kapal kayu

Diharapkan dengan penggunaan program aplikasi ini memudahkan dalam kegiatan di lokasi galangan kapal kayu dimana sebagian besar pekerja adalah lulusan dari SMA. Untuk memudahkan dalam penggunaan program ini juga telah dibuatkan modul mengenai program Fishing Vessel Construction.

\section{METODOLOGI}

Kegiatan ini merupakan kegiatan pengabdian masyarakat yang berupa KKN-PPM tematik yang didanai oleh Dikti pada tahun 2015 dimana tim pengabdian merupakan lintas bidang dari 3 jurusan yang ada pada Fakultas Teknik Universitas Diponegoro serta mahasiswa KKNPPM tematik merupakan dari tiga fakultas yang berbeda.

Secara garis besar kegiatan KKN-PPM tematik ini digolongkan menjadi 2 kegiatan yaitu

1. Kegiatan monodisiplin merupakan kegiatan program kerja yang dilaksanakan oleh mahasiswa KKN yang sesuai dengan ilmu yang ditekuninya

2. Kegiatan multi disiplin merupakan kegiatan program kerja yang dilaksanakan oleh mahasiswa KKN yang pelaksanaanya akan melibatkan mahasiswa lebih dari satu fakultas
Tahapan kegiatan KKN-PPM ini akan dimulai dari mencari permasalahan yang terdapat pada pengrajin kapal kayu tradisional kemudian merumuskan solusi yang dapat menjadi

1. Persiapan dan Pembekalan KKN-PPM

Pada kegiatan KKN-PPM ini kegiatan yang diutamakan adalah pengenalan teknologi perkapalan pada masyarakat pengrajin kapal kayu yang masih membangun kapal secara tradisional maka diharapkan mahasiswa dapat memberikan transfer pengetahuan mengenai proses membangun kapal secara modern, penggunaan gambar teknik pada pembangunan kapal. Mahasiswa akan diberikan pembekalan mengenai aspek pengetahuan teknologi perkapalan maka agar tercapainya tujuan kegiatan KKN-PPM.

\section{Pelaksanaan Kegiatan KKN-PPM}

Agar tercapainya tujuan KKN-PPM ini maka dalam pelaksanaan KKN ini dibuat volume pekerjaan mahasiswa pada masa KKN dalam bentuk Jam Kerja Efektif Mahasiswa(JKEM). Satuan dalam JKEM merupakan 1 jam efektif yang dilaksanakan mahasiswa dalam suatu kegiatan dimana total mahasiswa akan melaksanakan total 153 JKEM selama melaksanakan kegiatan KKN-PPM di pengrajin kapal kayu kabupaten Batang

\section{HASIL DAN PEMBAHASAN}

Kegiatan KKN-PPM yang dilaksanakan pada kabupaten Batang dimulai pada Mei 2015 yang meliputi perekrutan mahasiswa serta pembekalan KKN. Penerjunan ke lokasi KKN dimulai dari 27 Juli hingga 29 Agustus 2015. Berdasarkan hasil dari survey awal dilapangan maka dibentuklah kluster dalam 3 kelompok yang dijabarkan sebagai berikut ;

1. Kluster Perancangan Kapal Dengan Software.

2. Kluster Produksi Galangan Kapal.

3. Kluster Pemberdayaan Masyarakat Pesisir sekitar Galangan Kapal.

\subsection{Program Kerja Monodisiplin}

Program kerja mahasiswa yang dilakukan pada kegiatan ini adalah yang berkaitan dengan bidang ilmu yang ditekuni oleh mahasiswa masing-masing dan di aplikasikan untuk menjawab permasalahan yang terdapat di masyarakat. Oleh karenanya kegiatan ini akan bersifat individual dan berkaitan dengan tema galangan kapal tradisional atau berkaitan dengan kegiatan di sekitar galangan kapal. Karena 
kegiatan monodisiplin berkaitan dengan bidang keilmuan mahasiswa maka program kerja akan berkaitan dengan mahasiswa yang mengikuti KKN-PPM tematik diantaranya Jurusan Teknik Perkapalan akan melakukan kegiatan yang berkaitan dengan bidang perkapalan maupun mahasiswa dari Fakultas lainnya. Dalam pelaksanaanya kegiatan KKN-PPM ini di ikuti oleh tiga Fakultas yaitu Fakultas Teknik, Fakultas Ilmu Perikanan dan Ilmu Kelautan dan Fakultas Ilmu Budaya. Untuk kegiatan monodisiplin dapat diuraikan menjadi beberapa kegiatan sebagai berikut :

a. Pengenalan Dunia Bawah Laut untuk anakanak Sekolah Dasar (SD)

b. Sosialisasi Kewirausahaan

c. Pengenalan Aquascape

d. Sosialisasi standarisasi reparasi kapal ikan sesuai dengan badan klasifikasi Indonesia atau klasifikasi lain.

e. Sosialisasi standarisasi reparasi kapal ikan sesuai dengan badan klasifikasi Indonesia atau klasifikasi lain.

f. Sosialisasi tentang cara penyimpanan ikan saat melaut dan membawa ke daratan

g. Sosialisasi Karier Dunia Perkapalan di sekolah SMA

h. Sosialisasi jenis-jenis alat tangkap yang efisien dan penyampaian dampak negatif dari alat tangkap trawl (pukat harimau) untuk lingkungan

i. Penanaman Jiwa Bahari ke Anak SD

j. Sosialisasi Tentang pentingnya APD (Alat Pelindung Diri)

k. Pembelajaran komputer dan Aplikasi software

1. Edukasi Bahaya Formalin Pada Produk Perikanan

m. Pengenalan Jenis Produk-Produk Hasil Perikanan

n. Sosialisasi pada Warga mengenai Pengenalan Alat Tangkap yang digunakan untuk Kapal Ikan

o. Sosialisasi Keselamatan dan Kesehatan Pekerja (K3)

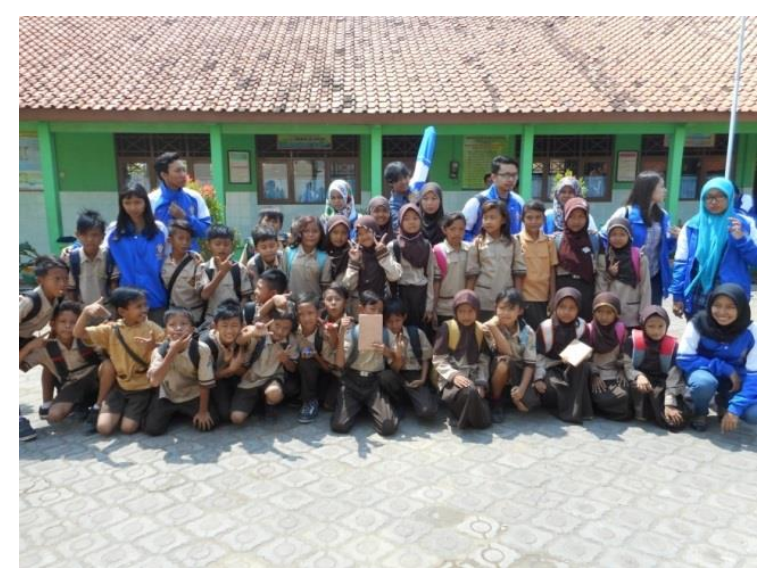

Gambar 5. Mahasiswa melakukan kegiatan Program Kerja monodisplin

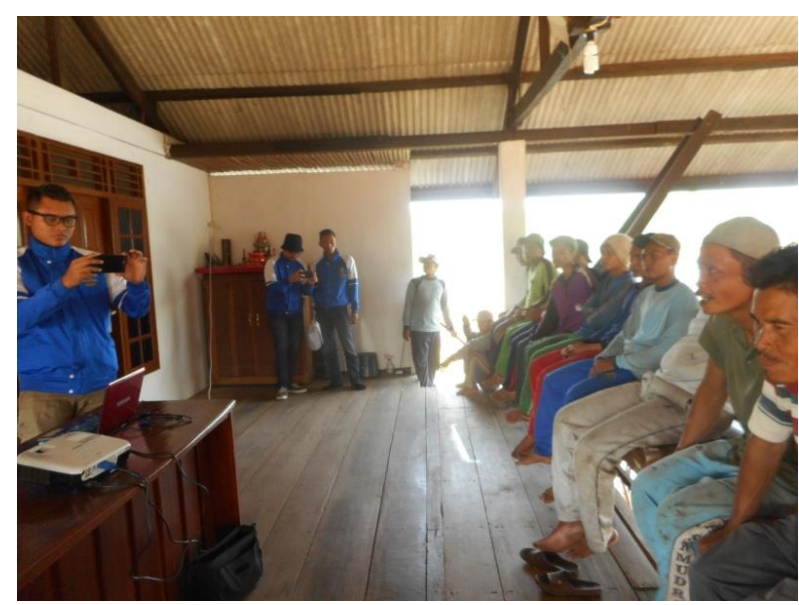

Gambar 6. Mahasiswa melakukan sosialisasi mengenai alat tangkap kapal perikanan

\subsection{Program Kerja Multidisiplin}

Program kerja mahasiswa yang dilakukan pada kegiatan ini dengan yang melibatkan lebih dari 1 bidang ilmu(multi) sehingga melibatkan lebih dari 1 mahasiswa dan lintas bidang keilmuan maka kegiatan yang dilaksanakan dapat bersifat kelompok. Oleh karenanya kegiatan ini akan bersifat kelompok dan berkaitan dengan tema galangan kapal tradisional atau berkaitan dengan kegiatan di sekitar galangan kapal yang telah disesuaikan dengan kelimuan masing-masing mahasiswa. Karena kegiatan multidisiplin berkaitan dengan lebih dari bidang keilmuan mahasiswa maka kegiatan akan memiliki tujuan kolektif yang bisa merupakan gabungan antara jurusan teknik perkapalan, jurusan teknologi perikanan maupun budidaya perikanan. Untuk kegiatan multidisiplin dapat diuraikan menjadi beberapa kegiatan sebagai berikut :

a. Pengenalan dan Pelatihan Penggunaan Software Delftship (Pembuatan Video 
Tutorial dan diupload ke Youtube untuk mempermudah dalam Pembelajaran Berikutnya)

b. Pengenalan dan pelatihan Software PROPCAD

c. Pengenalan dan Pelatihan Penggunaan Software FISHIPRO v.2.0

d. Pengenalan dan Pelatihan Penggunaan Software Fishing Construction

e. Pengenalan Software AutoCAD dalam bidang perkapalan(Pembuatan Modul Pelatihan AutoCAD)

f. Pengenalan pelatihan Software Maxsurf

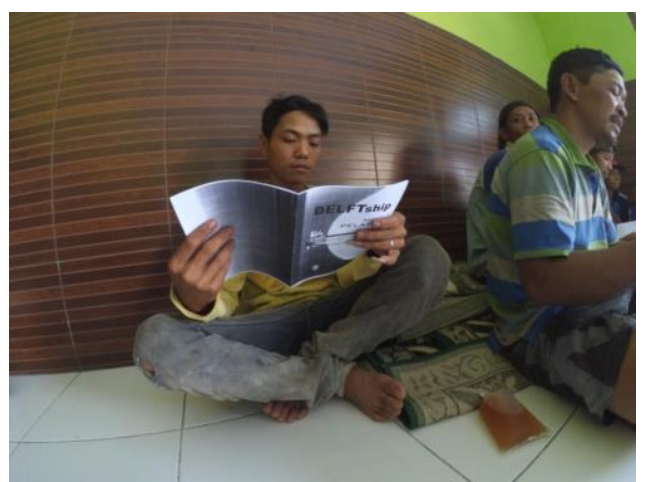

Gambar 7. Pelatihan perancangan kapal dengan Delftship.

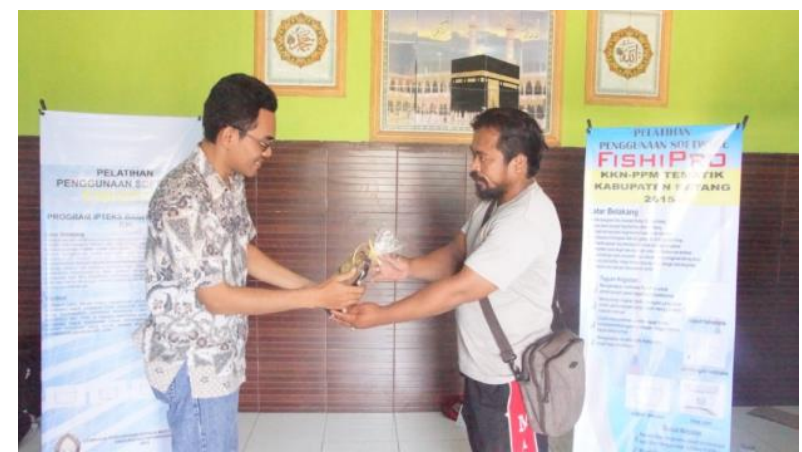

Gambar 8. Pemberian kenang-kenangan kepada salah satu peserta pelatihan fishipro

\section{KESIMPULAN DAN SARAN}

\subsection{Kesimpulan.}

Berdasarkan hasil dari kegiatan KKN-PPM Tematik 2015 di Karangasem Utara kabupaten Batang dapat disimpulkan sebagai berikut

1. Program Fishipro yang telah dikembangkan membantu para pengrajin kapal kayu untuk memahami gambar teknik kapal kayu tipe Batang.

2. Program KKN-PPM ini membantu pengrajin untuk meningkatkan kemampuan dalam alat bantu proses desain dengan Fishipro maupun Delftship.

3. Meningkatkan kesadaran warga akan keberadaan galangan kapal kayu yang menunjang sektor perikanan didaerah Karangasem.

4. Meingkatkan kesadaran pekerja untuk penggunaan alat keselamatan dan kesadaran akan kecelakaan kerja atau K3

\subsection{Saran}

Beberapa saran yang diperlukan untuk kesempurnaan KKN-PPM tematik ini di masa yang datang adalah sebagai berikut

1. Perlunya sosialisasi pentingnya pendidikan dikalangan masyarakat pesisir, karena hampir pekerja digalangan kapal kayu hanya berpendidikan SMP.

2. Perlunya pemantauan dan sinkronisasi kegiatan dengan pusat kegiatan $\mathrm{KKN}$ di Universitas agar kegiatan KKN dapat terselenggara sesuai dengan Pola Pokok Ilmiah Universitas

\section{UCAPAN TERIMA KASIH}

Penulis ingin mengucapkan terima kasih atas dibiayainya kegiatan KKN-PPM ini oleh Direktorat Riset dan Pengabdian Masyarakat Kementerian Riset, Teknologi dan Pendidikan Tinggi dengan Nomor : 012 / SP2H / PPM / DIT.LITABMAS / II / 2015

\section{DAFTAR PUSTAKA}

[1] Ardidja, Supardi. 2007. Kapal Penangkap Ikan. Sekolah Tinggi Perikanan. Jakarta

[2] Trimulyono, Andi dkk. 2013. Pemberdayaan Masyarakat Pesisir Di Kabupaten Batang Jawa Tengah Melalui Pengembangan Industri Galangan Kapal Tradisional. Laporan Akhir KKN-PPM, Semarang

[3] Biro Klasifikasi Indonesia, 1996. Buku Peraturan Klasifikasi dan Konstruksi Kapal Kayu. BKI. Jakarta.

[4] Masrul, Melly, 2009. Pengukuran Kapal Perikanan. Balai Besar Pengembangan Penangkapan Ikan. Semarang

[5] Ngumar, H.S, 2004. Identifikasi Ukuran Kapal. Departemen Pendidikan Nasional, Direktorat Jendral Pendidikan Dasar dan Menengah, Direktorat Pendidikan Menengah Kejuruan. Jakarta 
[6] Sub Direktorat Rancang Bangun Dan Konstruksi Kapal Perikanan, 2004, Profil Kapal Perikanan. Departemen KelautanDan Perikanan Direktorat Jenderal Perikanan Tangkap. Jakarta

[7] Rahardjo ,Oktavian. 2008. Pengaruh Bentuk Buritan Dan Penempatan Sistem Penggerak Terhadap Kinerja Kapal Ikan Tradisional. Tesis Magister FTK, ITS

[8] Wahyono, Agung. 2011. Kapal Perikanan (Membengun Kapal Kayu). Balai Besar Pengembangan Penangkapan Ikan.

Semarang. 